\title{
Uterine Artery Embolization and Pregnancy. Actual and Controversial Issues of Gestation Terms and Delivery
}

\author{
Julia E. Dobrokhotova, PhD, ScD*; Igor I. Grishin, PhD; Djamilya M. Ibragimova, PhD; \\ Inessa G. Knysheva; Vera J. Ilchenko \\ N.I. Pirogov Russian National Research Medical University \\ Moscow, the Russian Federation
}

\begin{abstract}
Background: The aim of this study was to estimate the particular qualities of pregnancy and delivery among patients after uterine artery embolization (UAE) for uterine fibroids.

Materials and Methods: The study included 161 pregnant women. We performed a comparative analysis of pregnancy and delivery among patients after UAE, patients with uterine fibroids without UAE, and healthy patients with physiological pregnancy and childbirth.

Results: The frequency of complications during pregnancy and delivery among patients after UAE for uterine fibroids was not significantly different from the frequency of complications among patients without uterine fibroids and significantly lower than the complication rate among patients with uterine fibroids without UAE.

Conclusion: UAE use is a highly efficient alternative to surgical or medical treatments for uterine fibroids in patients of reproductive age, which plan pregnancy.(Int J Biomed. 2016;6(1):33-37.).
\end{abstract}

Keywords: uterine fibroids; uterine artery embolization; pregnancy; childbirth.

\section{Introduction}

Global trends in the reproductive health field are difficult to assess, but numerous studies have shown that many indicators of women's reproductive function have declined over the past half-century [1]. The effect of uterine artery embolization (UAE) on fertility remains unclear but is certainly relevant [2]. There is not enough data to evaluate the impact of UAE on fertility, pregnancy and its outcomes among women. Quite often, the presence of uterine fibroids occurs among women with infertility, although, according to some data, benign tumors are associated with infertility only in $5 \%-10 \%$ of cases, when all other causes of reproductive function disorders are excluded [3].

However, the exact role of fibroids in infertility and the periodic loss of pregnancy is uncertain. The complexity of assessing the impact of fibroids on fertility is primarily due

*Corresponding author: Professor Julia E. Dobrokhotova, $P h D, S c D$. Head of Department of Obstetrics and Gynecology, Medical Faculty, N.I. Pirogov Russian National Research Medical University, Moscow, the Russian Federation.E-mail:pr.dobrohotova@mail.ru to the patient's age, since the frequency of fibroids increases with age, and fertility decreases. Still, the absolute effects are physiological and anatomical factors, associated with the presence of uterine fibroids, which may contribute to the state of infertility in the population [4].

Among some researchers, there is a perception that the $\mathrm{UAE}$ is the reason for the decline of ovarian reserve, resulting in a greatly reduced possibility of pregnancy [5]. N. Berkane et al. suggested that one of the possible causes of failures with respect to infertility after the UAE may not be an unintended embolization of ovaries and endometrium, but the presence of confounding factors, such as age and the mere presence of uterine fibroids [6].

Other data show a decrease of reproductive potential after the procedure of UAE by perfusion violations in endometrium and the development of various pathological processes [7], which, according to G.Pron et al., may be the cause of failure to conceive and poor outcomes of pregnancies [8].

Thus, the data about pregnancy and childbirth after UAE, described in the literature, is very controversial, presented in separate reports on the fact of pregnancy and childbirth, and do not disclose the features of the gestation 
period. At the Department of Obstetrics and Gynecology of Medical Faculty, UAE, including the treatment of uterine fibroids, has been applied since 2003, and, for the moment, we have the experience of more than 1,500 technically successful embolizations. With a decade of experience in the application of this intervention, as well as a sufficient number of successful pregnancies and births after UAE, we found it necessary and urgent to carry out this study, the aim of which was to study the particular qualities of pregnancy and childbirth in this category of patients.

\section{Materials and Methods}

We conducted clinical and laboratory analysis of the course of pregnancies, childbirths and the postpartum periods in 161 patients. All patients were divided into three groups. Group 1 included 59 pregnant women, who underwent UAE as a treatment for uterine fibroids; Group 2 included 67 pregnant women with uterine fibroids diagnosed before pregnancy and treated with medical therapy, or had no treatment at all; Group 3 included 35 pregnant women without uterine fibroids with physiological pregnancy and childbirths (control group).

Clinical examination included a thorough medical history, with the explanation of all diseases and surgical procedures, a physical examination, a special obstetric examination, and a laboratory examination in full accordance with the standards of healthcare with the involvement of all specialists according to relevant indications.

The study was conducted in accordance with ethical principles of the Declaration of Helsinki and approved by N.I. Pirogov Russian National Research Medical University Ethics Committee. Written informed consent was obtained from all participants.

Statistical analysis was performed using the statistical software «Primer of Biostat 4.0» and «STATISTICA 7». Group comparisons with respect to categorical variables are performed using chi-square tests with Yates correction or, alternatively, Fisher's exact test when expected cell counts were less than 5. A probability value of $P<0.05$ was considered statistically significant.

\section{Results}

Spontaneous abortion occurred in $4 / 6.8 \%$ patients of Group 1 and in 12/17.9\% patients of Group 2; the number of patients that remained under further observation was 55 women in each group. In Group 3, 3/8.6\% pregnancies ended with a spontaneous abortion; an artificial abortion was carried out (according to the patients' requests) in $2 / 5.7 \%$ of cases, which eventually led to a reduction of the number of patients to 30 .

Analyzing the complications of the first trimester of gestation, we revealed the following features. The threat of spontaneous abortion up to 13 weeks was noticed in $18.2 \%$ of patients in Group I and 16.6\% of patients in Group 3, which was significantly different in comparison with $38.2 \%$ in Group $2(P=0.0197$ and $P=0.0397$, respectively). It should be noted that hospitalization and in-patient treatment in Group 2 were required in $18 / 85.7 \%$ patients identified with the threat of termination of pregnancy $(\mathrm{n}=21)$. These data are significantly different from data in Groups 1 and 3.

We believe that a decrease in the incidence of threatened abortion among patients after UAE compared to patients without UAE is due to the shutdown of the pathological channel of fibroids from the main bloodstream, and the absence of a number of hormonal imbalances that a growing uterine fibroid provokes during pregnancy. The frequency of pregnancy complications are presented in Table 1.

Table 1.

Pregnancy complications among patients of the studied groups

\begin{tabular}{|l|c|c|c|c|c|c|}
\hline \multirow{2}{*}{$\begin{array}{c}\text { Pregnancy } \\
\text { complications }\end{array}$} & $\begin{array}{c}\text { Group 1 } \\
(\mathrm{n}=55)\end{array}$ & \multicolumn{2}{c|}{$\begin{array}{c}\text { Group } 2 \\
(\mathrm{n}=55)\end{array}$} & \multicolumn{2}{c|}{$\begin{array}{c}\text { Group 3 } \\
(\mathrm{n}=30)\end{array}$} \\
\cline { 2 - 7 } & $\mathrm{abs}$ & $\%$ & $\mathrm{abs}$ & $\%$ & $\mathrm{abs}$ & $\%$ \\
\hline \multicolumn{7}{|c|}{ The 1st trimester of pregnancy } \\
\hline Threatened abortion & 10 & $18.2^{*}$ & 21 & $38.2 * *$ & 5 & 16.6 \\
\hline \multicolumn{7}{|c|}{ The 2nd trimester of pregnancy } \\
\hline Threatened abortion & 2 & $3.6^{*}$ & 16 & $29.1 * *$ & - & - \\
\hline \multicolumn{7}{|c|}{ Threatened preterm } \\
birth
\end{tabular}

* $-P<0.05$ between Group 1 and Group 2; ** $-P \leq 0.05$ between Group 2 and Group 3.

An abnormal placenta location, before 13 weeks of pregnancy, was identified in $29.1 \%$ of cases in Group 2, which was significantly different compared to $5.5 \%$ in Group 1 $(P=0.0025)$ and $0.0 \%$ in Group $3(P=0.0000)$. Differences between Group 1 and Group 3 were not significant. There were no statistically significant differences between patients of all three groups in other pregnancy complications in the first trimester.

The threat of spontaneous abortion in the second trimester was diagnosed in 3.6\% of patients in Group 1, which was not significantly different from Group 3. In Group 2, this complication was diagnosed in $29.1 \%$ of cases. The differences between Group 2 and Groups 1 and 2 were reliable $(P=0.0008$ and $P=0.0028$, respectively). Abnormal placenta location in the second trimester remained in $12 / 21.8 \%$ patients of Group 2. Pathological placenta location in the second trimester of pregnancy was not found in Groups 1 and 3.

Uterine fibroids node malnutrition up to 22 weeks of pregnancy was diagnosed in $4 / 7.3 \%$ patients of Group 2. Among these patients, the initial size of the myomatous node was more than $5 \mathrm{~cm}$ in diameter and had a tendency to growth in the second trimester. We noted no cases of myomatous node malnutrition among patients of Group 1. In this group, a significant increase of myomatous node $(10 \%$ or more) is diagnosed in only $1 / 1.8 \%$ pregnant woman, that was significantly different from Group 2, in which the most pronounced growth of the nodes was identified among 
$9 / 16.4 \%$ patients $(P=0.0203)$. According to the literature, the level of myometrium epidermal growth factor increases during pregnancy and in myomatous nodes which have an extensive vascular supply $[9,10]$. Massive changes occur in the receptor apparatus of the myometrium, characterized by increasing the number of receptors for progesterone and estradiol [11]. The totality of these factors can lead to a remarkable growth of myomatous nodes during pregnancy and may be accompanied by many complications. The application of UAE, as a method of treatment of uterine fibroids, makes it possible to avoid the development of these complications associated with the growth of fibroids in Group 1.

The threat of preterm labor in the third trimester among Group 1 patients was found in $1.8 \%$ of cases, which was significantly different from Group $2(25.5 \%, P=0.0009)$ and did not differ from Group $3(0.00 \%, P>0.05)$. In connection with the threat of premature birth, in-patient treatment was needed in $57.1 \%$ of cases in Group 2. In Group 1, the treatment was carried out on an outpatient basis. Preterm labor was not identified in Group 3.

The frequency of preeclampsia was significantly lower in Group 1 than in Group $2(P=0.0006)$ and was not statistically different from Group 3. Thus, according to our data, the incidence of preeclampsia among patients who underwent UAE is not different from the frequency of preeclampsia cases during normal pregnancy. UAE has no pathological influence on the formation of placenta blood vessels and does not increase the risk of preeclampsia.

Rates of placental insufficiency formation (PI) in Group $1(10.9 \%)$ and Group $3(0.00 \%)$ were significantly lower compared with Group $2(50.9 \%)(P=0.0000$ and $P=0.0000$, respectively). We noticed an early PI development (up to 30 weeks of pregnancy) among patients of Group 2. At the same time, a severe course of PI, poorly treatable with medical correction, was also more frequent in Group 2. However, in contrast to the total number of patients with PI, the difference was not statistically significant.

Thus, the course of pregnancy in a group of patients after UAE had no statistically significant differences from the course of pregnancy in patients without uterine fibroids. Complications of pregnancy were significantly more frequent in Group 2. In general, the pregnancy course in Group 1 may be characterized as a physiological behaviour, comparable with the control group.

Labor at term occurred in 53/96.4\% patients of Group 1, 47/85.5\% patients of Group 2 and 30/100\% patients of Group 3. Figure 1 shows the overall rate of birth complications (delay amniorrhexis, primary weakness of labor activity, secondary weakness of labor activity, intrauterine hypoxia, discoordination of labor activity, placental pathology) in all three groups according to periods.

The overall rate of complications in the 1 st and $3 \mathrm{rd}$ periods of delivery was significantly higher in Group 2 compared to Group 1 and Group 3. Statistically significant differences during labor among pregnant women of Group 1 and Group 3 were not observed.

The frequency of cesarean section (C-section) was significantly higher in Group 2 (21/38.2\%) compared to Group
$1(10 / 18.2 \%, P=0.0341)$ and Group $3(5 / 16.6 \%, P=0.0397)$. Planned C-section was performed in $8 / 14.5 \%$ patients of Group 1, in $9 / 16.4 \%$ patients of Group 2, and in 4/13.35\% patients of Group 3. An emergency C-section was performed in $2 / 3.6 \%$ patients of Group 1 and $1 / 3.35 \%$ patient of Group 3 , that was significantly lower than in Group $2(12 / 21.8 \%$ patients; $P=0.01$ and $P=0.05$, respectively).
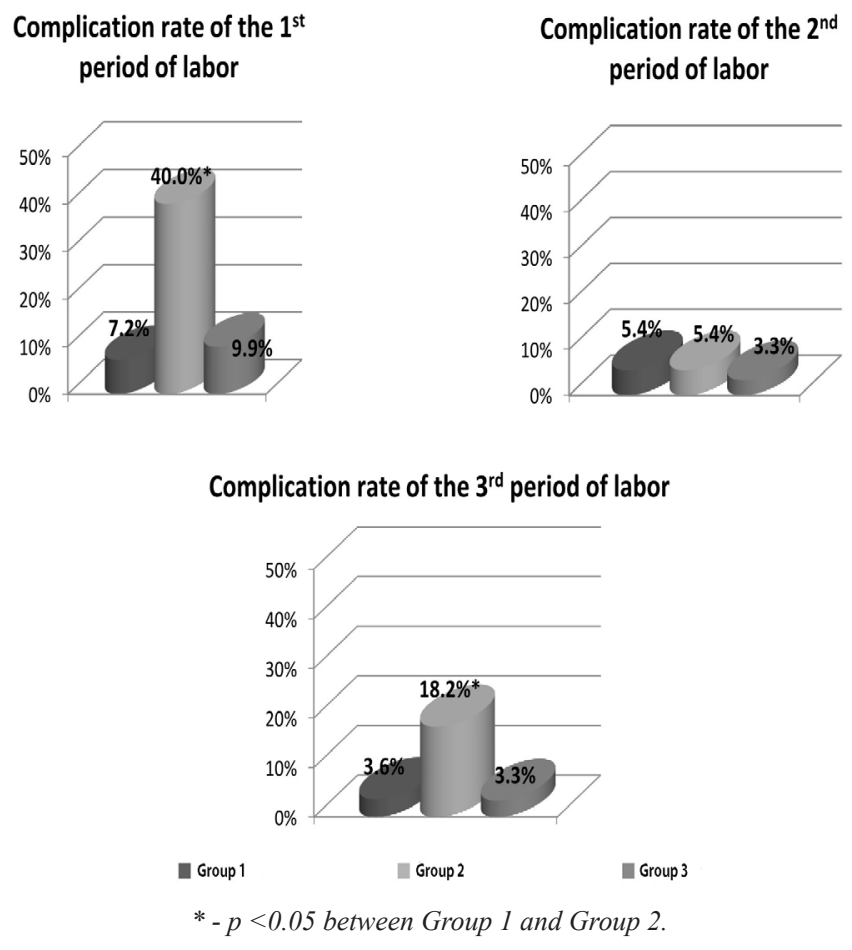

Fig. 1. The overall rate of birth complications among patients of studied groups

Analysis of C-sections performed in three groups of patients revealed that UAE in anamnesis among Group 1 patients was not an indication for abdominal delivery in any case. The frequency of C-section, both in the planning and in the emergency order, was not different from that in the control group and coincided with the population-wide indicators, which apparently proves that pregnancies and childbirths among patients after UAE occur physiologically.

\section{Discussion}

Despite numerous reports of successful pregnancies after UAE, the feasibility of this method of treatment for uterine fibroids among patients of reproductive age is still very debatable.

According to J.P. Pelage et al. [11] and M.D. Levie [12], as well as some other authors, among patients of reproductive age who are planning to retain their reproductive function, UAE is not an optimal way to treat fibroids [13-15]. The authors substantiate their opinions by noting that there is a lack of sufficient data on the effect of embolization on pregnancy and childbirth, as well as possible further complications. 
In some literature, we can find reports on the development of preterm menopause among patients after embolization, as well as the development of such complications as necrosis of embolized fibroids, fistula formation, pyometra and purulent endometritis, leading to the necessity of hysterectomy, intrauterine adhesions, endometrium atrophy, including the development of permanent amenorrhea with intact ovarian function [16-22].

According to another researchers, the frequency of pregnancies after embolization ranges from $23 \%$ to $61 \%$ [2324]. Thus, in the study of Firouznia et al. [25], 14(61\%) women of the 23 patients planning a pregnancy became pregnant, and 9 patients in the first time. McLucas et al. consider that the possibility of pregnancy after embolization is not less than after the conservative myomectomy [26].

We could not find enough evidential data in literature, which would allow us to allocate clear criteria under which the patient will not have any contraindications for pregnancy after UAE. Most sources indicate that this issue was solved purely individual $[27,28]$. We also found that the number of fibroids, uterine size and type of fibroid before embolization, affect on the onset of pregnancy after UAE, which is most likely, due to the successful outcome of UAE. However, pregnancies outcomes (labors, miscarriages, non-developing pregnancies, abortions) are not different from that among patients without uterine fibroids.

\section{Conclusion}

In sum, we can conclude that UAE has no adverse effect on pregnancy and childbirth. The frequency of complications during pregnancy, childbirth and the postpartum period among patients underwent, is not significantly different from patients without uterine fibroids. UAE is not a contraindication for pregnancy and childbirth, and not a reason for abortion. Thus, UAE use is a highly efficient alternative to surgical or medical treatments for uterine fibroids in patients of reproductive age, which plan pregnancy.

\section{Competing interests}

The authors declare that they have no competing interests.

\section{References}

1. Foster WG, Neal MS, Han MS, Dominguez MM. Environmental contaminants and human infertility: hypothesis or cause for concern. J Toxicol Environ Health B Crit Rev. 2008;11(3-4):162-76.

2. Mohan PP, Hamblin MH, Vogelzang RL. Uterine artery embolization and its effect on fertility. J Vasc Interv Radiol. 2013; 24(7): 925-30.

3. Khaund A, Lumsden MA. Impact of fibroids on reproductive function. Best Pract Rese Clin Obstet Gynaecol. 2008; 22(4):749-60.

4. Imaoka I, Wada A, Matsuo M, Yoshida M, Kitagaki H, Sugimura K. MR imaging of disorders associated with female infertility: use in diagnosis, treatment, and management.
Radiographics. 2003; 23(6):1401-21.

5. ACOG Committee Opinion. Uterine artery embolization. Committee on Gynecologic Practice, American College of Obstetricians and Gynecologists. Obstet Gynecol. 2004;103(2):403-4.

6. Berkane N, Moutafoff-Borie C. Impact of previous uterine artery embolization on fertility. Curr Opin Obstet Gynecol. 2010;22(3):242-7.

7. Mara M, Horak P, Kubinova K, Dundr P, Belsan T, Kuzel D. Hysteroscopy after uterine fibroid embolization: evaluation of intrauterine findings in 127 patients. J Obstet Gynaecol Res. 2012; 38(5):823-31.

8. Pron G, Mocarski E, Bennett J, Vilos G, Common A, Vanderburgh L; Ontario UFE Collaborative Group. Pregnancy after uterine artery embolization for leiomyomata: the Ontario multicenter trial. Obstet Gynecol. 2005;105(1):67-76.

9. Mikhalevich SI, Kapusta AV. Pregnancy, childbirth and the postpartum period among women with uterine fibroids. Medical News. 2011;2:18-25.[Article in Russian].

10. Samoilova TE. Uterine fibroids. Justification of nonoperative treatment (review). Reprod Problems. 2003;9(4):3236. [Article in Russian].

11. Pelage JP,Walker WJ, Le Dref O, Rymer R. Ovarian artery: angiographic appearance, embolization and relevance to uterine fibroid embolization. Cardiovasc Intervent Radiol. 2003; 26(3):227-33.

12. Levie MD. Uterine artery embolization: Laparoscopic myomectomy. FIGO World Congress of Gynecology and Obstetrics (16th 2000 Washington DC). NY: Elsevier; 2000.

13. Hutchins FL Jr, Worthington-Kirsch R. Embolotherapy for myoma-induced menorrhagia. Obstet Gynecol Clin North Am. 2000; 27(2):397-405.

14. Goodwin SC, Bonilla SC, Sacks D, Reed RA, Spies JB, Landow WJ, et al. Reporting standards for uterine artery embolization for the treatment of uterine leiomyomata. J Vacs Interv Radiol 2003; 14(9 Pt2):S467-76.

15. Honda I, Sato T, Adachi H, Kobayashi Y, Shimada K, Watanabe H, Okada Y, Inoue M. Uterine artery embolization for leiomyoma: complications and effects on fertility. Nihon Igaku Hoshasen Gakkai Zasshi. 2003;63(6):294-302. [Article in Japanese].

16. Sakhautdinova IV. Uterine artery embolization is a uterine-conserving surgical method for fibroids treatment. Perm Med Zh. 2006;23(3):126-36. [Article in Russian].

17. Chitrit Y, Zafy S, Pelage JP, Ledref O, Khoury R, Caubel P. Amenorrhea due to partial uterine necrosis after uterine artery embolization for control of refractory postpartum hemorrhage. Eur J Obstet Gynecol Reprod Biol. 2006;127(1):140-2.

18. Gaia G, Chabrot P, Cassagnes L, Calcagno A, Gallot $\mathrm{D}$, Botchorishvili R, et al. Menses recovery and fertility after artery embolization for PPH: a single-center retrospective observational study. Eur Radiol. 2009;19(2):481-7.

19. Guo WB, Yang JY, Chen W, Zhuang WQ. Amenorrhea after uterine fibroid embolization: a report of six cases. Ai Zheng. 2008;27(10):1094-9. [Article in Chinese].

20. Dewdney SB, Mani NB, Zuckerman DA, Thaker PH. Uteroenteric fistula after uterine artery embolization. Obstet Gynecol. 2011;118(2 Pt 2):434-6.

21. Maheux-Lacroix S, Lemyre M, Laberge PY, Lamarre A, Bujold E. Uterine artery embolization complicated by uterine perforation at the site of previous myomectomy. J Minim Invasive Gynecol. 2012;19(1):128-30.

22. Donnez O, Jadoul P, Squifflet J, Donnez J. Unusual 
complication after uterine artery embolization and laparoscopic myomectomy in a woman wishing to preserve future fertility. Fertil Steril. 2008;90(5):2007.e5-9.

23. Kapranov SA, Breusenko VG, Dobrokhotova JE, Kurtser MA, Bobrov BJ, Krasnova IA. Uterine artery embolization: a modern view on the problem. Part 1. Diagn Interv Radiol. 2007;1:72-87. [Article in Russian].

24. Bradley LD. Uterine fibroid embolization: a viable alternative to hysterectomy. Am J Obstet Gynecol. 2009;201(2):127-35.

25. Firouznia K, Ghanaati H, Sanaati M, Jalali AH, Shakiba M. Pregnancy after uterine artery embolization for symptomatic fibroids: a series of 15 pregnancies. AJR Am J Roentgenol. 2009;192(6):1588-92.

26. McLucas B, Perrella R, Adler L. Embolization for the treatment of adenomyosis. AJR Am J Roentgenol 2002; 178(4):1028-9.

27. Murvatov KD, Obelchak IS, Myshenkova SA, Adamyan LV. Uterine artery embolization is minimally invasive method for uterine fibroid treatment (review). Probl Reprod. 2004; 6:43-50. [Article in Russian].

28. McLucas B. Pregnancy following uterine artery embolization: an update. Minim Invasive Ther Allied Technol. 2013;22(1):39-44. 